\title{
Metais pesados provenientes de rejeitos de mineração e seus efeitos sobre a saúde e o meio ambiente
}

\author{
Daphne Heloisa de Freitas Muniz ${ }^{*}$ \\ Eduardo Cyrino Oliveira-Filho**
}

\begin{abstract}
RESUMO - O aumento nas concentrações de metais pesados no solo e na água próximos a zonas de mineração pode estar relacionado com processos químicos e biológicos que controlam a solubilidade, a disponibilidade e a mobilidade desses metais. Os efeitos tóxicos dos metais pesados no ser humano estão associados aos compostos orgânicos e inorgânicos por eles formados e são determinados pela quantidade do metal envolvida e pelo tempo de exposição. Com base em revisão bibliográfica, o presente artigo enfoca e discute aspectos relevantes sobre o estudo de metais, como arsênio, cádmio, cromo e mercúrio, provenientes de rejeitos de mineração.
\end{abstract}

Palavras-chave: Metais pesados. Mineração. Rejeitos. Toxicologia.

\section{Heavy metals of mining rejects and its effects on the health and the environment}

\begin{abstract}
The increase in the concentrations of heavy metals in soil and water close to mining zones can be related with chemical and biological processes that control the solubility, readiness and mobility of these metals. The toxic effects of the heavy metals on the human being are associated to its organic and inorganic compositions. These effects are determined by the amount of metals and the time of exposure. Based in a literature review, the present article focuses and discusses important aspects of the study of metals as arsenic, cadmium, chromium and mercury as dangerous mining rejects.
\end{abstract}

Keywords: Heavy metals. Mining. Rejects. Toxicology.

\footnotetext{
* Graduada em Química e pós-graduanda em Gestão Ambiental pela Universidade Estadual de Goiás.

** Pesquisador da Embrapa Cerrados e Professor de Toxicologia na FACS/UniCEUB. Embrapa Cerrados - BR 020 Km 18. Planaltina, DF - Brasil - CEP 73310-970. Caixa Postal: 08223. Fone: (61) 3388-9898 Fax: (61)3388-9879. cyrino@cpac.embrapa.br
} 


\section{Introdução}

A poluição do solo e de sistemas aquáticos por metais pesados é um fator que afeta a qualidade do meio ambiente e constitui risco eminente de intoxicação ao homem. Nos últimos anos, foram realizadas inúmeras pesquisas com a finalidade de avaliar os possíveis impactos ambientais relacionados ao aumento da concentração de metais pesados no meio ambiente. Esses metais são originários de processos litogênicos e/ou atividades antrópicas, como a utilização de fertilizantes em zonas agrícolas e a atividade mineradora.

As ações antrópicas são responsáveis por adições de até 1,16 milhões de toneladas de metais por ano em ecossistemas terrestres e aquáticos no mundo todo (NRIAGU; PACYNA, 1988). No Brasil, a mineração de níquel, ouro, ferro e de outros metais de interesse comercial, têm contribuído com a liberação de rejeitos que se constituem como uma das principais formas de contaminação do solo e da água por metais pesados. $\mathrm{O}$ aumento nas concentrações desses rejeitos no solo e nos efluentes próximos a zonas de mineração pode estar relacionado com processos químicos e biológicos que controlam a solubilidade, a disponibilidade biológica e a mobilidade desses metais (GUILHERME et al., 2005).

A redução dos impactos causados pela poluição do solo e da água é fundamental para a melhoria da qualidade ambiental e garantia de qualidade de vida. Grande parte das técnicas para remediar e minimizar os impactos sobre o solo e água, contaminados por metais pesados, têm sido desenvolvidas para resolver problemas locais, devendo ser adaptadas em função das variações e das condições do meio.

O presente trabalho tem como objetivo enfocar e discutir aspectos relevantes do estudo de metais pesados, como arsênio (As), cádmio $(\mathrm{Cd})$, cromo $(\mathrm{Cr})$ e mercúrio $(\mathrm{Hg})$, provenientes de rejeitos de mineração.

\section{Fontes de metais pesados no solo e na água}

Os metais pesados estão presentes naturalmente no meio ambiente, mesmo que não haja ação antrópica o aumento em sua concentração pode ocorrer tanto por processos naturais quanto por atividades humanas. $\mathrm{O}$ intemperismo e a lixiviação do 
solo são exemplos de processos naturais que geram o aparecimento de metais pesados na água e no solo, todavia a extração e o beneficiamento de metais, rejeitos industriais, efluentes domésticos, insumos agrícolas, descarte de produtos comerciais, queima de combustíveis fósseis e descarte de lodo de esgoto são atividades antrópicas associadas à contaminação do meio ambiente por tais metais (NRIAGU; PACYNA, 1988; TEIXEIRA et al., 2000; ALLEONI et al., 2005; GUILHERME et al., 2005).

\section{Mineração}

O conjunto de operações realizadas visando à retirada de minério do depósito mineral é chamado lavra, e o depósito mineral em lavra é denominado mina. Esta designação é aplicada mesmo que a extração tenha sido suspensa. A lavra pode ser executada de modo bastante simples, por meio de atividades manuais ou por meios altamente mecanizados e em larga escala, como ocorre nas grandes minerações (TEIXEIRA et al., 2000).

O minério bruto não se encontra suficientemente puro ou adequado para que seja submetido a processos metalúrgicos ou para a utilização industrial. Assim, após a lavra, os minérios são submetidos a um tratamento ou beneficiamento, que os torna aptos à utilização. $\mathrm{O}$ tratamento divide o minério bruto em duas frações: concentrado e rejeito. Este último é a fração constituída quase que exclusivamente pelos "minerais de ganga" minerais presentes nas jazidas, e que, devido a aspectos econômicos, tecnológicos ou composicionais, não são utilizados.

Atualmente, junto às grandes metrópoles brasileiras, é comum a existência de enormes áreas degradadas, resultantes de atividades de extração de metais. Essas atividades são desenvolvidas a céu aberto e, na maioria das vezes, propiciam a ação de processos erosivos, pois não obedecem a um planejamento de lavra adequado (RELATÓRIO..., 2002). A degradação da área é uma conseqüência inerente ao processo de mineração. A intensidade da degradação depende do volume, do tipo de mineração e dos rejeitos produzidos.

$\mathrm{Na}$ extração e no beneficiamento do caulim, um tipo de argila empregada na fabricação de vários produtos comerciais, ocorre produção de rejeitos líquidos, lançados nos rios, e sólidos, geralmente aterrados. Esses rejeitos podem conter, além de outros contaminantes, concentração de metais, como o cádmio $(\mathrm{Cd})$, acima do 
permitido pela legislação (SILVA et al., 2001). Os reflexos dessa contaminação extravasam, freqüentemente, os limites das áreas de trabalho, atingindo a topografia, a flora, a fauna, além dos sistemas hídrico e morfofisiológico do solo.

No caso de contaminação por mercúrio $(\mathrm{Hg})$, a atividade garimpeira de ouro é bastante significativa, pois é uma das mais antigas de que se tem conhecimento. Processos físico-químicos de extração de ouro, como a amalgamação, são importantes fontes de contaminação do meio ambiente, pois o metal passa na forma de vapor ou por meio dos rejeitos minerais, que podem chegar às águas e ao solo (GALVÃO; COREY, 1987d).

Além da contaminação por mercúrio, a cianetação constitui outro agravante na extração de ouro. Uma vez esgotados os minérios de mais fácil lavra e extração, os mineradores depararam com as dificuldades de extração de ouro fino e ouro associado a sulfetos, para os quais as técnicas de separação gravítica e amalgamação não se mostram muito eficientes. Este processo baseia-se na capacidade do cianeto $\left(\mathrm{CN}^{-}\right)$em formar complexo com o ouro. Este íon é utilizado na cianetação sob a forma de sais, como o cianeto de sódio, $\mathrm{NaCN}$, de potássio, $\mathrm{KCN}$, e de cálcio $\mathrm{Ca}(\mathrm{CN})_{2}$. O cianeto é uma substância letal ao homem, tendo em vista a competição entro o íon cianeto e o íon férrico presente na meta-hemoglobina (CIMINELLI; GOMES, 2002).

As fontes e o potencial disponível de cromo $(\mathrm{Cr})$ foram investigados em solos ultramáficos de Niquelândia-GO, com extrações químicas de níquel associado à atividade mineralógica, a fim de avaliar a biodisponibilidade e o impacto na biodiversidade do solo. Para isso, estudos mineralógicos foram realizados no solo de uma topossequência em Niquelândia (GARNIER et al., 2006).

Os impactos causados pela exploração e pelo beneficiamento do minério de ferro foram avaliados em uma mina localizada em Minas Gerais. Os testes indicaram que o resíduo acumulado tem capacidade de retenção de cromo $(\mathrm{Cr})$ e que os sedimentos acumulados (formados principalmente pelo mineral goethita) funcionam na retenção de metais pesados e diminuem a dispersão de poluentes (PIRES et al., 2003).

No Porto de Santana-AP, nas dependências da antiga mineradora de manganês (Mn) ICOMI, há uma fonte de risco de contaminação ambiental representada pela área de deposição e pela antiga bacia de rejeito da mineradora. Análises físico-químicas das águas dos poços de monitoramento indicaram que os teores de arsênio (As) e de 
manganês são elevados na área industrial da antiga mineradora (SANTOS et al., 2003).

Nas etapas de lavra e beneficiamento de carvão mineral, ocorre disposição de resíduos sólidos estéreis e rejeitos constituídos por materiais carbonosos e minerais sem valor comercial. Estes rejeitos, também são ricos em sulfetos de ferro que se oxidam em presença do ar, da água e da ação da bactéria Thiobacillus ferroxidans, desencadeando a acidificação de drenagens e a dissolução de metais, originando a drenagem ácida de mina (DAM). A DAM contém íons metálicos dissolvidos (As, $\mathrm{Cd}, \mathrm{Cu}, \mathrm{Ni}, \mathrm{Pb}, \mathrm{Zn}, \mathrm{Al}$, $\mathrm{Cr}, \mathrm{Hg}, \mathrm{Mg}, \mathrm{Mn}$ ) em composições e concentrações que dependem de condições geológicas específicas (FUNGARO, 2005).

As atividades de lavra e processamento mineral podem contribuir para a poluição das águas superficiais e subterrâneas, caso não haja controle rigoroso das operações envolvidas. Atenção especial deve ser dada aos processos erosivos e de assoreamento que ocorrem nas minas e nas pedreiras, aos depósitos de material estéril permanente e de minério lixiviado, à área da usina de concentração e aos locais de descarte de água, entre outros (OLIVEIRA; LUZ, 2001).

\section{Comportamento e disponibilidade de alguns metais pesados no solo e na água}

Seja qual for o caminho, natural ou antrópico, pelo qual os metais pesados alcançam o solo e a água, a composição total encontrada é de pouca utilidade para avaliar sua disponibilidade aos organismos (ALLEONI et al., 2005). O transporte de metais pesados no solo não é facilmente medido. No entanto, esse assunto é de grande importância, sobretudo se considerados os riscos que podem acarretar à qualidade das águas superficiais e subterrâneas, além dos elevados custos envolvidos em operações de remediação (SOARES et al., 2005). Na cinética dos metais no solo, é comum o processo de formação de depósitos minerais que ocorrem também em solos subjacentes a unidades de disposição de rejeitos de mineração. Seu estudo pode, portanto, ser útil para a previsão da contaminação do solo nessas localidades.

Embora seja o solo uma barreira natural de proteção aos aquíferos, os fatores que governam sua capacidade em reter metais pesados são extremamente complexos, o que dificulta o seu entendimento e as possibilidades de previsão acerca do comportamento desses elementos, principalmente a longo prazo. Sabe-se que a maior ou 
a menor mobilidade dos metais pesados é determinada pela caracterização do solo e pelos teores de matéria orgânica e inorgânica que influenciarão as reações de precipitação, dissolução, adsorção, dessorção, complexação e oxirredução (OLIVEIRA; MATTIAZZO, 2001). Os graus de mobilidade, atividade e biodisponibilidade dos metais pesados também dependem de fatores, como: $\mathrm{pH}$, temperatura, potencial redox, CTC (capacidade de troca catiônica), competição com outros metais, ligação com ânions e composição, além da força iônica da solução do solo (OLIVEIRA; COSTA, 2004).

Em suma, a disponibilidade dos metais pesados depende da presença do elemento na solução do solo, a qual é governada pela composição e pela reação dos sistemas, pelas condições de oxirredução e pela cinética das reações, que dependem de características do solo e da tendência em formar compostos precipitados insolúveis e coprecipitados com outros minerais, formar complexos com matéria orgânica e adsorver outros minerais.

\section{Toxicidade dos metais pesados}

Todos os metais e seus compostos possuem toxicidade, ou seja, a capacidade inerente que um elemento químico tem para causar efeitos adversos sobre os organismos vivos. O fator-chave é o grau de exposição que afeta o organismo. A exposição está relacionada tanto com a quantidade envolvida como com o tempo de exposição (GOYER, 1996).

Os efeitos tóxicos dos metais pesados e dos compostos de metais são determinados pelo índice e o alcance com que os metais ou compostos se convertem em uma forma biodisponível. Ao ingressar no ambiente, os íons livres do metal podem ligar-se com matéria orgânica, reduzindo à quantidade que está biodisponível.

O excesso de metais pesados, como o mercúrio, por exemplo, tem efeitos tóxicos reconhecidos. As quantidades traço de mercúrio em formas inertes disseminamse no meio ambiente. Quando os solos são perturbados por atividades antrópicas como a mineração, o mercúrio que se encontra em sua forma natural em contato com o solo e a flora transforma-se rapidamente em formas móveis. Logo chega às cadeias alimentares por meio dos peixes e passam a outros níveis como, aves, mamíferos e seres humanos 
(JEFFERY, 2001).

\section{Toxicidade para peixes}

Os peixes, por serem consumidores e pertencerem ao nível superior do ecossistema aquático, acumulam grande quantidade de poluentes persistentes, isso explica a grande importância destes organismos em testes de toxicidade (MÖLLERKE et al., 2003). A presença de metais, como cádmio, mercúrio, arsênio e selênio no ambiente aquático, pode afetar adversamente a saúde dos peixes. Em particular, os mecanismos que protegem os peixes contra doenças são mais afetados (ANDERSON; ZEEMAN, 1995).

\section{Arsênio}

Em estudo sobre a toxicidade do arsênio, trutas arco-íris (Salmo gairdneri) foram alimentadas com dieta que continha arsenito de sódio em concentrações de 10, 20 e $30 \mathrm{mg} / \mathrm{kg}$ (equivalentes a 0,$2 ; 0,4$ e $0,6 \mathrm{mg} / \mathrm{kg}$ do peso úmido dos peixes por dia) por 8 semanas. As doses em que se observou o acúmulo de arsênio em diferentes tecidos variaram de 1,28 a $1,52 \mathrm{mg} / \mathrm{kg}$ (peso seco) para o músculo, de 1,55 a $5,21 \mathrm{mg} / \mathrm{kg}$ para o fígado, de 0,84 a $1,88 \mathrm{mg} / \mathrm{kg}$ para as brânquias e de 1,21 a $1,98 \mathrm{mg} / \mathrm{kg}$ para a pele (OLADIMEJI et al., 1984).

Em outro estudo de 144 dias, o efeito da temperatura, praticamente, não alterou a toxicidade do arsenito sobre a espécie de truta arco-íris Oncorhynchus mykiss, já que as $\mathrm{CLs}_{50}$ encontradas foram de 17,7 e $20,7 \mathrm{mg} / \mathrm{L}$ em $5^{\circ} \mathrm{C}$ e $15^{\circ} \mathrm{C}$, respectivamente. A maior parte dos dados sobre efeitos do arsênico em peixes estão baseados nos testes de toxicidade aguda, que medem a mortalidade dos peixes em 96 horas. Alguns efeitos subletais, tais como, alteração no crescimento, no comportamento e na fertilização, também são avaliados (MCGEACHY; DIXON, 1989). No Brasil, um estudo avaliou, quanto à presença de arsênio, 27 amostras de peixes piava (Leporinus obtusidens) e 27 de pintado (Imelodus maculatus), capturados no Lago Guaíba, em Porto Alegre (RS). Os níveis encontrados estavam abaixo de $1,0 \mathrm{mg} / \mathrm{kg}$, limite permitido pela legislação vigente para peixes e seus produtos. A média encontrada nas piavas e nos pintados foi de $0,14 \mathrm{mg} / \mathrm{kg}$. Os resultados sugeriram que mais estudos de monitoramento com outras 
espécies de peixes do lago fossem realizados, de modo a subsidiar autoridades de preservação ambiental para proteção da saúde humana e qualidade dos alimentos (MOLLERKE et al., 2003).

\section{Cádmio}

A toxicidade do cádmio para peixes marinhos e de água doce foi avaliada em estudos científicos sob diferentes condições de temperatura e oxigenação da água. Em geral, conforme o aumento na concentração de sais dissolvidos na água, há redução da toxicidade e, com a elevação da temperatura, ocorre o inverso. Foi observado também que o aumento no teor de oxigênio dissolvido (OD) na água reduz a toxicidade do cádmio para os peixes de água doce. Os salmonídeos parecem ser mais suscetíveis ao metal. Vários efeitos subletais foram observados, incluindo significativa presença de malformações na espinha dorsal (THE INTERNATIONAL PROGRAMME ON CHEMICAL SAFETY, 1992b ).

\section{Cromo}

Vários estudos sobre a toxicidade do cromo foram realizados com espécies aquáticas, tais como, peixes e microcrustáceos. Dependendo da espécie, o cromo pode ser mais ou menos tóxico para peixes na água aquecida. Com o aumento do $\mathrm{pH}$ ou da dureza da água foi observada a redução na toxicidade do metal. O cromo pode deixar os peixes mais suscetíveis a infecções em decorrência de alterações no sistema imunológico, e as concentrações elevadas podem danificar e ou acumular-se em vários tecidos desses animais (THE INTERNATIONAL PROGRAMME ON CHEMICAL SAFETY, 1988). Outros fatores influenciam a disponibilidade do cromo e, conseqüentemente, sua toxicidade. Entre eles, está a presença de outros minerais e alguns poluentes orgânicos.

O cromo VI é acumulado nas espécies aquáticas por difusão passiva (U. S. ENVIRONMENTAL PROTECTION AGENCY, 1978). O estado e a atividade fisiológica dos peixes também afetam a acumulação. Um estudo analisou os órgãos e os tecidos do peixe da espécie Leuciscus rutilus e encontrou concentrações de cromo no fígado, nas brânquias e no intestino entre 30 e $37,5 \mathrm{mg} / \mathrm{kg}$, valores de 10 a 30 vezes 
maiores do que as concentrações encontradas no coração, na pele, nos músculos e nas escamas (REICHENBACH-KLINKE, 1977).

\section{Mercúrio}

O mercúrio inorgânico é tóxico para peixes, mesmo em concentrações baixas. Testes de 96 horas mostraram que as $\mathrm{CLs}_{50}$ variaram entre 33 e $400 \mu \mathrm{g} / \mathrm{L}$ para peixes de água doce e que esses valores foram mais elevados para peixes de água salgada. Os compostos orgânicos do mercúrio são mais tóxicos. A toxicidade é afetada pela temperatura, pela salinidade, pelo oxigênio dissolvido e pela dureza da água. Grande variedade de anomalias fisiológicas e bioquímicas foi relatada após a exposição dos peixes a concentrações subletais do mercúrio. A reprodução também foi afetada adversamente pelo metal (THE INTERNATIONAL PROGRAMME ON CHEMICAL SAFETY, 1989).

Em outro estudo, trutas arco-íris foram expostas, por 96 horas, a concentrações de cloreto de mercúrio, variando entre 0 e $2 \mathrm{mg} / \mathrm{L}$. Em temperaturas de 5, de 10, e de $20^{\circ} \mathrm{C}$, foram determinadas $\mathrm{CL}_{50} \mathrm{~s}$ de 0,$4 ; 0,28$ e $0,22 \mathrm{mg} / \mathrm{L}$, respectivamente. $\mathrm{Em} 10^{\circ} \mathrm{C}$, a $\mathrm{CL}_{50}$ nas primeiras 24 horas para o cloreto de mercúrio (composto inorgânico) foi, aproximadamente, 30 vezes mais alta (em termos de concentração do mercúrio) do que para o acetato de fenilmercúrio (composto orgânico) (MACLEOD; PESSAH, 1973).

\section{Toxicidade para mamíferos}

\section{Arsênio}

As formas inorgânicas e orgânicas do arsênio podem causar efeitos adversos em animais de laboratório. O grau de toxicidade do arsênio depende basicamente da forma do composto (se inorgânico ou orgânico) e do estado de oxidação do elemento. Geralmente, os compostos inorgânicos do arsênio são considerados mais tóxicos do que os orgânicos, e, entre estas, duas classes, as formas trivalentes $\left(\mathrm{As}^{3+}\right)$ são mais tóxicas do que as formas pentavalentes $\left(\mathrm{As}^{5+}\right)$, pelo menos em doses muito elevadas. Diversos órgãos de diferentes sistemas são afetados pelo arsênio, incluindo a pele e os sistemas respiratório, cardiovascular, imunológico, reprodutivo, gastrointestinal e nervoso (THE 


\section{INTERNATIONAL PROGRAMME ON CHEMICAL SAFETY, 2001).}

Um modelo de estudo recentemente relatado pode ser uma ferramenta útil para os estudos futuros de carcinogenicidade. Nesse estudo, as fêmeas de ratos foram expostas à água para beber, contendo arsênio na concentração de $500 \mu \mathrm{g} / \mathrm{L}$, por 2 anos. Os resultados mostraram aumento na incidência de tumores envolvendo, principalmente, o pulmão, o fígado, o trato gastrointestinal e a pele. $\mathrm{O}$ arsênio inorgânico não induz mutações in vivo. Entretanto, o arsênio pode produzir aberrações no cromossomo in vitro, afetar a metilação e o reparo do DNA (THE INTERNATIONAL PROGRAMME ON CHEMICAL SAFETY, 2001).

\section{Cádmio}

Os efeitos tóxicos do cádmio em animais experimentais são influenciados por fatores genéticos, nutritivos e por interações com outros metais (com zinco em particular). Um estudo recente, com duração de 18 meses, expôs ratos continuamente, pela via inalatória, a um aerossol com baixa concentração de cloreto de cádmio. Os resultados mostraram incidência elevada de câncer de pulmão, com evidência preliminar significativa da relação entre dose e resposta. A inalação do cádmio em níveis elevados causa edema pulmonar letal (THE INTERNATIONAL PROGRAMME ON CHEMICAL SAFETY, 1992a).

Em estudo pela via oral, foi observado que a ingestão de dose elevada causou a necrose do ovário e dos testículos de inúmeros animais, além da não-ovulação e vários danos no fígado. As doses maiores danificaram a mucosa gástrica e intestinal. A exposição a longo prazo por inalação e a administração intratraqueal causaram danos inflamatórios crônicos nos pulmões. A administração oral por longo prazo produziu efeitos primeiramente nos rins, mas também no fígado e nos sistemas imunológico, ósseo e cardiovascular. Os efeitos teratogênicos e os danos na placenta dependem da relação entre a exposição e o período da gestação e podem envolver efeitos interativos com o zinco (THE INTERNATIONAL PROGRAMME ON CHEMICAL SAFETY, 1992a). 


\section{Cromo}

Estudo realizado com este elemento mostrou que doses acima de $10 \mathrm{mg} / \mathrm{kg}$ de cromo hexavalente $\left(\mathrm{Cr}^{6+}\right)$ na dieta afetaram o trato gastrointestinal, os rins e o sistema hematológico. Os efeitos tóxicos do cromo trivalente foram relatados somente pela administração parenteral. Estudos em animais experimentais foram conduzidos com compostos de cromo no intuito de reproduzir o câncer similar àquele encontrado no homem, quando exposto ao cromo. A maioria dos testes envolveu exposições subcutâneas, intramusculares ou via injeção intrapleural. Além disso, diversos compostos hexavalentes do cromo foram administrados aos ratos por via intrabronquial, implantação ou instilação intratraqueal. Compostos relativamente insolúveis, como o cromato de cálcio, o cromato de estrôncio e determinados compostos de cromato de zinco, produziram carcinomas broncogênicos. O cromato de lítio e o cromato de bário produziram respostas fracas. Há evidências suficientes de que determinados compostos hexavalentes de cromo são carcinogênicos para animais experimentais. Não foi observado aumento na incidência de tumores com relação aos compostos trivalentes em testes pela via oral, entretanto as doses administradas eram baixas. Outros experimentos com o cromo hexavalente evidenciaram vários danos genéticos em testes de mutagenicidade de curto prazo, incluindo danos no DNA, e incorporação dos nucleotídeos na transcrição do DNA. Em alguns estudos, o tricloreto de cromo $\left(\mathrm{CrCl}_{3}\right)$ foi encontrado acumulado no núcleo da célula (até $20 \%$ do índice celular de cromo) (THE INTERNATIONAL PROGRAMME ON CHEMICAL SAFETY, 1988).

\section{Mercúrio}

Em um estudo com coelhos, foram encontradas evidências de danos no cérebro, nos rins, no coração, e nos pulmões de animais expostos ao vapor de mercúrio em concentração de $29 \mathrm{mg} / \mathrm{m}^{3}$ de ar. Os primeiros efeitos foram vistos após 1 hora de exposição, e as mudanças severas subseqüentes resultaram após exposições mais longas (ASHE et al., 1983).

Os sintomas de intoxicação aguda, provenientes do mercúrio, consistem em choques, colapso cardiovascular, falha renal e danos gastrointestinais severos. Os 
prejuízos irreversíveis são definidos como danos celulares ou no órgão, o qual não é reparado mesmo após exposição. Alguma melhoria na função ou na condição do tecido contaminado pode ocorrer, mas a recuperação nunca é completa. Como exemplo dos danos reversíveis, pode-se destacar a regeneração das células e a restauração das funções após a exposição (THE INTERNATIONAL PROGRAMME ON CHEMICAL SAFETY, 1976).

\section{Toxicidade para o ser humano}

Para os seres humanos, os efeitos adversos causados pela exposição aos metais pesados estão relacionados mais com a exposição funcional do que com os níveis gerais de metais no ambiente. Isto se aplica tanto aos trabalhadores do setor de mineração, industrial ou agrícola, quanto às pessoas que utilizam compostos de metais pesados diretamente em suas ocupações (JEFFERY, 2001).

\section{Arsênio}

As relações do homem com o arsênio possuem características especiais. Os problemas de saúde produzidos pelo metal dependem da forma de As ingerido, da dose, da freqüência e do tempo de absorção. No organismo humano, o As é rapidamente excretado pelo fígado e pelos rins, que funcionam como verdadeira usina de eliminação de excesso, tanto para o arsênio inorgânico quanto para o orgânico (SANTOS et al., 2003).

Seus efeitos adversos sobre a saúde são variados e vão desde lesões da pele até quadros clínicos graves dos sistemas gastrointestinal, circulatório periférico e nervoso. É também um agente carcinógeno, pois causa câncer de pele e pulmão (GALVÃO; COREY, 1987a ).

A exposição humana não-ocupacional ao arsênico ocorre pela ingestão de alimentos e de água. $\mathrm{O}$ alimento é o contribuinte principal à entrada diária do arsênico total. Os solos contaminados, como pedras salientes de minas, são fonte potencial de exposição ao arsênio (THE INTERNATIONAL PROGRAMME ON CHEMICAL SAFETY, 2001). 


\section{Cádmio}

A presença natural de cádmio no meio ambiente, aparentemente, não tem causado problemas significativos para a saúde humana, pois encontra-se em baixas concentrações. Porém, a ampla utilização na indústria faz com o cádmio seja um dos mais freqüentes contaminantes do meio ambiente. $\mathrm{O}$ conhecimento de seus efeitos na saúde ganhou terreno com o reconhecimento da doença de itai-itai, cujo nome decorre pelas dores ósseas e musculares nos afetados. A doença foi descrita após a contaminação dos alimentos por cádmio originado em uma mina na cidade de Toyama, Japão (GALVÃO; COREY, 1987b ).

A maioria dos estudos de grupos epidemiológicos disponíveis, tanto de observações como de estudos clínicos, foram executados em trabalhadores expostos ao metal ou em populações japonesas de áreas contaminadas por cádmio. Muitos destes estudos focalizaram-se na detecção de disfunção dos rins. Outros investigaram sinais clínicos de doenças, como pedra renal e insuficiência pulmonar. Até a metade dos anos 70, atenção particular foi dada ao Japão na detecção de doenças nos ossos (por exemplo, a doença de itai-itai). Em outros estudos, o papel do cádmio na carcinogenicidade e na mortalidade de seres humanos também foi relatado. A exposição ao cádmio produz uma extensa variedade de efeitos adversos envolvendo muitos órgãos e sistemas. Do ponto da vista da medicina preventiva, a detecção de efeitos adversos nos rins é de fundamental importância, a fim de impedir efeitos mais sérios nos pulmões ou nos ossos. Com relação à exposição aguda de seres humanos, os efeitos mais considerados estão na inalação, que afeta os pulmões, e ocasionam danos crônicos aos rins, os quais, depois da exposição prolongada, são considerados órgãos críticos. Uma conseqüência da disfunção tubular renal é o distúrbio do metabolismo do cálcio e da vitamina D. De acordo com alguns estudos, isto pode levar à osteoporose, efeito esse não confirmado por outros autores, contudo danos na calcificação óssea não podem ser descartados (THE INTERNATIONAL PROGRAMME ON CHEMICAL SAFETY, 1992a ).

\section{Cromo}

O cromo é encontrado na natureza em várias combinações com outras substâncias e pode apresentar-se na forma de íons com valência $+2,+3$ ou +6 . Entre as 
mais importantes quanto aos seus aspectos sobre a saúde humana, destacam-se a trivalente $(+3)$, essencial para o metabolismo humano, e a hexavalente $(+6)$, cromo potencialmente tóxico. A presença de altas concentrações da forma hexavalente no ambiente, principalmente de fontes antrópicas, é nociva à saúde, já que causa problemas de caráter local, tais como, dermatite irritativa, dermatite alérgica, corrosão da mucosa nasal, e outros de caráter geral, como asma bronquial, câncer de pulmão e danos renais (GALVÃO; COREY, 1987c ).

Estudos clínicos e epidemiológicos em adultos evidenciaram que a dose oral letal foi de 50 a $70 \mathrm{mg} / \mathrm{kg}$ de peso corpóreo para cromatos. As características clínicas mais importantes produzidas depois da entrada foram necrose do fígado e dos rins, e contaminação de órgãos vitais, como o coração. O cromo hexavalente causa irritação no trato respiratório. A ulceração e a perfuração do septo nasal têm sido relatadas nos trabalhadores expostos ao cromato oriundo do beneficiamento e de indústrias que usam o cromo hexavalente. Além disso, a inalação e o contato do septo nasal com mãos contaminadas contribuem à exposição nasal.

Rinites, broncoespasmos e pneumonia podem resultar da exposição aos compostos hexavalentes. Os compostos de cromato, principalmente o cromato de sódio e o dicromato do potássio causam irritação da pele, e ulcerações podem ocorrer no local da irritação. A exposição ao cromo trivalente não produz tais efeitos. Determinadas pessoas manifestam reações alérgicas na pele ao cromo hexavalente e, possivelmente, ao trivalente. As reações da pele com a exposição dermal ao cromo são descritas por contato com cromato, que é o alérgeno mais comum (THE INTERNATIONAL PROGRAMME ON CHEMICAL SAFETY, 1988).

Os efeitos crônicos da exposição ao cromo ocorrem no pulmão, no fígado, nos rins, no trato gastrointestinal e no sistema circulatório, principalmente a exposição industrial excessiva da pele ao cromo hexavalente, quando associado com a pele irritada, ou a inalação do cromo transportado pelas vias aéreas ou de poeira misturada. Riscos teratogênicos da exposição ao cromo não foram relatados para seres humanos. Os resultados de estudos epidemiológicos em vários países demonstraram que os homens que trabalhavam no beneficiamento de cromato, antes de 1950, apresentaram elevada taxa de carcinoma broncogênico, se comparados aos homens do grupo controle. Por causa do período longo entre a exposição inicial e a detecção do câncer, da falta de 
dados sobre a extensão e tipo de exposição, a relação entre a dose e a resposta não foi quantificada. Dados obtidos posteriormente mostraram claramente que, embora o risco do câncer nos trabalhadores em minas modernas tenha sido reduzido, o problema ainda remanesce (THE INTERNATIONAL PROGRAMME ON CHEMICAL SAFETY, 1988).

\section{Mercúrio}

Fatores físico-químicos, como temperatura, $\mathrm{pH}$ e potencial de oxirredução, influem nos processos de formação de vapor de mercúrio e nas formas orgânicas de mercúrio, podem incrementar os riscos para a saúde humana e favorecer a formação de compostos perigosos, como os derivados de alquilmercúrio que apresentam forte tendência à bioacumulação (GALVÃO; COREY, 1987d ). Os danos causados ao organismo humano por compostos mercuriais são principalmente aqueles que afetam o sistema nervoso em forma reversível e irreversível, segundo a dose e a duração da exposição. Os sintomas característicos da exposição ao vapor de mercúrio são: excitabilidade, irritabilidade, perda da memória, insônia, tremor e gengivites. Os da exposição ao metilmercurio são: parestesia, redução do campo visual, dificuldade auditiva e ataxia (THE INTERNATIONAL PROGRAMME ON CHEMICAL SAFETY, 1976).

\section{Considerações finais}

A atividade mineradora vem desempenhando um importante papel na sociedade através dos tempos, contudo essa exploração se realizada de maneira não planejada pode afetar a qualidade de vida das futuras gerações. A mineração é um dos setores básicos da economia de muitos países, contribuindo, de forma decisiva, para o bemestar e a melhoria da qualidade de vida, desde que seja operada com responsabilidade social, utilizando sempre os princípios do desenvolvimento sustentável. A prevenção e a minimização de impactos causados sobre o meio ambiente são os melhores aliados em termos de sustentabilidade, e isso pode ocorrer quando há um planejamento e uma correta avaliação de impacto ambiental tanto no início da lavra da jazida e como após o 
fechamento da mina.

Um dos grandes problemas da mineração na atualidade está relacionado com os rejeitos decorrentes dessa atividade, como a extração de ouro, caulim e carvão mineral, pois contribuem para o aumento de metais pesados no solo e em sistemas aquáticos. Esses metais muitas vezes estão associados a problemas de contaminação do ambiente e do próprio ser humano. Para determinar a ocorrência destes metais no meio ambiente, é necessário compreender os processos que controlam a sua mobilidade e que os tornam biodisponíveis. Uma vez que o animal ou o ser humano pode entrar em contato com esses contaminantes, torna-se necessário conhecer, entre outras coisas, a toxicidade desses compostos, para evitar desastres históricos como os que se tem notícia.

\section{Referências}

ALLEONI, L.R.F.; BORBA, R.P. \& CAMARGO, O.A. Metais pesados: da cosmogênese aos solos brasileiros. Tópicos em Ciências do Solo, v. 4, p. 1-42, 2005.

ANDERSON, D.P. \& ZEEMAN, M.G. Immunotoxicology in Fish. In: RAND, G.M. (Ed.). Fundamentals of aquatic toxicology: effects, environmental fate, and risk assessment. Washington: Taylor \& Francis, 1995. p. 371-404

ASHE, W.F. et al. Behavior of mercury in the animal organism following inhalation. Archives of Industrial Hygiene and Occupational Medicine, v. 7, n. 1, p. 19-43, 1953.

CIMINELLI, V.S.T.; GOMES, A.D. Princípios de Cianetação. In: TRINDADE , R.B.E.; BARBOSA-FILHO, O. (Eds.). Extração de ouro: princípios, tecnologia e meio ambiente. Rio de Janeiro: CETEM/MCT, 2002. p.322.

FUNGARO, D.A. Tratamento de drenagem ácida de mina utiliza zeólitas sintetizadas a partir de cinzas de carvão. Revista Meio Filtrante, n. 18, 2005. Disponível em: $<$ http://www.meiofiltrante.com.br/meterias.asp?action=detalhe\&id=193>. Acesso em: 02 fev. 2007.

JEFFERY, W.G. A world of metals: finding, making and using metals. 2nd ed. Ottawa: ICME, 2001. 60 p.

GALVÃO, L.A.C.; COREY, G. Arsenico. México: OPS; OMS, 1987a. 70 p. (Serie Vigilância, 3).

Cadmio. México: OPS; OMS, 1987b. 69 p. (Serie Vigilância, 4)

Cromo. México: OPS; OMS, 1987c. 66 p. (Serie Vigilância, 5) 
Mercurio. México: OPS; OMS, 1987b. 82 p. (Serie Vigilância, 7)

GARNIER, J. et al. Solid speciation and availability of chromium in ultramafic soils from Niquelândia, Brazil. Journal of Geochemical Exploration, v. 88, p. 206-209, 2006.

GOYER, R. A. Toxic Effects of Metals. In: KLAASSEN, C.D. (Ed.). Casarett \& Doull's toxicology: The basic science of poisons, New York: McGraw Hill, 1996. p. 691-736.

GUILHERME, L.R.G. et al. Elementos-traço em solos e sistemas aquáticos. Tópicos em Ciências do Solo, v. 4, p. 345-390, 2005.

McGEACHY, S.M.; DIXON, D.G. The impact of temperature on the acute toxicity of arsenate and arsenite to rainbow trout (Salmo gairdneri). Ecotoxicology Environmental Safety, v. 17, n. 1, p. 86-93, 1989.

MACLEOD, J.C.; PESSAH, E. Temperature effects on mercury accumulation, toxicity, and metabolism rate in rainbow trout (Salmo gairdneri). Journal of the Fisheries Research Board of Canada, v. 30, p. 485-492, 1973.

MÖLLERKE, R.O. et al. Níveis de arsênio total como indicador biológico, na avaliação da qualidade do pescado (Leporinus obtusidens e Pimelodus maculatus) do lago Guaíba em Porto Alegre RS-Brasil. Revista do Instituto Adolfo Lutz, v. 62, n. 2, p. 117 - 121 , 2003.

NRIAGU, J.O.; PACYNA, J.M. Quantitative assessment of worldwide contamination of air, water and soils with trace metals. Nature, v. 33, p. 134-139,1988.

OLADIMEJI, A.A.; QADRI, S.U.; FREITAS, A.S.W. Long-term effects of arsenic accumulation in rainbow trout, Salmo gairdneri. Bulletin of Environmental Contamination and Toxicology, v. 32, p. 732- 741, 1984.

OLIVEIRA, T.S.; COSTA, L.M. Metais pesados em solos de uma topolitossequência do Triângulo Mineiro. Revista Brasileira de Ciências do Solo, v. 28, p. 785-796, 2004.

OLIVEIRA, A.P.A.; LUZ, A.B. Recursos hídricos e tratamento de águas na mineração. Rio de Janeiro: CETEM/MCT, 2001.36 p. (Série Tecnologia Ambiental, 24).

OLIVEIRA, F.C.; MATTIAZZO, M.E. Mobilidade de metais pesados em um latossolo amarelo distrófico tratado com lodo de esgoto e cultivado com cana-de-açúcar. Scientia Agricola, v. 58, n. 4, p. 807-812, 2001.

PIRES, J.M.M. et al. Potencial poluidor de resíduo sólido da Samarco Mineração: estudo de caso da barragem de Germano. Revista Árvore, v. 27, n. 3, p. 393-397, 2003. 
REICHENBACH-KLINKE, H.H. Fish diseases and harm suffered by fish 2nd ed., Stuttgart: Gustav Fischer, 1977. 474 p.

RELATÒRIO perspectivas do meio ambiente no Brasil: GEO-BRASIL, 2002. Brasília: CPRM, março 2002. 31 p.

SANTOS, E.C.O. et al. Exposição ao mercúrio e ao arsênio em Estados da Amazônia: síntese dos estudos do Instituto Evandro Chagas/FUNASA. Revista Brasileira de Epidemiologia, v. 6, n. 2, p. 171-185, 2003.

SILVA, A.C.; VIDAL, M.; PEREIRA, M.G. Impactos ambientais causados pela mineração e beneficiamento de caulim. Revista Escola de Minas, v. 54, n. 2, p. 133136, 2001.

SOARES, P.S.M.; YOKOYAMA, L.; FREIRE, D.D.C. Transporte de metais pesados no solo no contexto da disposição de resíduos sólidos. Rio de Janeiro: CETEM/MCT, 2005, 45 p. (Série Tecnologia Ambiental, 33)

TEIXEIRA, W. et al. Decifrando a Terra. São Paulo: Oficina de Textos, 2000. 568 p.

THE INTERNATIONAL PROGRAMME ON CHEMICAL SAFETY. Environmental Health Criteria, 1 Mercury. Geneva: WHO, 1976. Disponível em: <http://www.inchem. org/documents/ehc/ehc/ehc001.htm>. Acesso em: 02 fev 2007.

Environmental Health Criteria, 61 Chromium. Geneva: WHO, 1988. Disponível em: <http://www.inchem.org/documents/ehc/ehc/ehc061.htm.>. Acesso em: 02 fev 2007.

Environmental Health Criteria, 86 Mercury: environmental aspects. Geneva: WHO, 1989. Disponível em: <http//:www.inchem.org/documents/ehc/ehc/ ehc086.htm>. Acesso em: 02 fev 2007.

Environmental Health Criteria, 134 Cadmium. Geneva: WHO, 1992a. Disponível em: <http://www.inchem.org/documents/ehc/ehc/ehc134.htm>. Acesso em: 02 fev 2007.

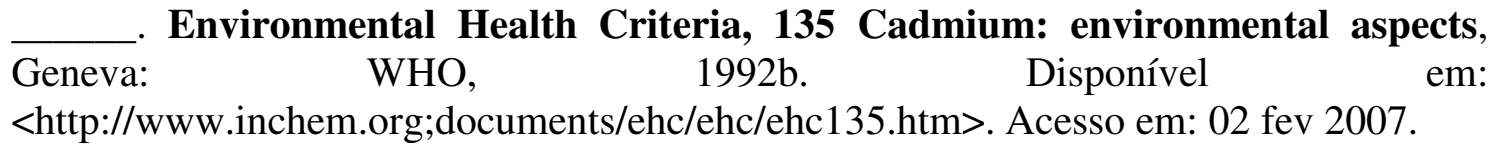

Environmental Health Criteria, 224 Arsenic and Arsenic Compounds. Geneva: WHO, 2001. Disponível em: <http://www.inchem.org/documents/ehc/ehc/ ehc224.htm. >. Acesso em: 02 fev 2007.

U.S. ENVIRONMENTAL PROTECTION AGENCY. Reviews of the environmental effects of pollutants. III. Chromium. Washington: USEPA, 1978. 285 p. 